\title{
BACTERIOLOGICAL INDEX IN LEPROSY
}

\section{R. G. COCHRANE}

Since the introduction of sulphone therapy several workers (Muir, Dharmendra, Cochrane) have realised the necessity for a method of assessing the degree of positivity in leprosy. Wade some years ago suggested the possibility of calculating a bacteriological index, but as far as is known this was not generally adopted. At the beginning of the therapeutic trials on the new sulphone drugs in leprosy, the author discussed with Dr. C. G. Pandit, the then Director of the King Institute, Guindy, Madras, the possibility of working out a bacteriologic index which could ultimately be used for statistical purposes. As a result of suggestions from Dr. Pandit and Dr. Ramanujam the following method was finally chosen:-

Sixteen smears are taken by Wade's slit method and graded from $6+$ to negative. Smears are graded as follows: $6+$, bacilli and many globi in every field examined; $5+$, bacilli and few globi in every field examined; $4+$, bacilli but no globi in every field examined; $3+$, bacilli in Io per cent or more fields examined; $2+$, bacilli in 4 per cent or more of fields examined. $I+$, bacilli in 2 per cent or more of fields examined. When the result is less than I + then Muir's method is adopted, the numerator being the number of bacilli and the denominator the number of fields examined, e.g. if in roo fields five bacilli were counted, the result would be $5 /$ Ioo. with sulphone therapy the bacilli break up into granules and are not easily counted, so if there were five groups of granules in 100 fields the result would be 5/I0o (granular). Half a point is recorded if the index is under one. The total number of readings are added up and divided by I6 and this gives a number which is taken to the nearest digit. The resultant figure is termed the " bacteriologic index." For instance, if an examination showed the following smear results:-

$$
\begin{aligned}
& 4 \text { smears } 6+(4 \times 6=24) \quad 24 \\
& 2, \quad 4+(2 \times 4=8) \quad 8 \\
& 5 \quad, 3+(5 \times 3=\text { I5) I5 } \\
& 5,, 2+(5 \times 2=\text { IO }) \text { IO } \\
& \text { Total } 57
\end{aligned}
$$

the bacteriologic index would be 57 divided by 16 , which is 3.56 or, to the nearest digit, 4 . When the index drops below 0.5 , then it is recorded as $>0.5$. Our criteria are as strict as possible. For 
instance, if only a few acid fast granules are found in one area of the I6 smears, the result is still recorded as >0.5. Naturally, therefore, in reporting results, the method of assessing the bacteriologic state of the patient must be noted, for if a few acid fast granules are considered of no importance and the patient in consequence is placed in the negative group, the negative rate will rise considerably. We, however, consider that the presence of bacilli, whether as granules, beaded forms or acid fast dust, are of importance and include such cases among our positive findings.

Other workers who have suggested a bacteriological index have used a less number of smears. Muir chose five and Dharmendra six. Muir's method is described as follows:-

"At each examination five smears were made from the skin at places where experience indicated the most bacilli were likely to be found, cutaneous and subcutaneous nodules being chosen when present. Each smear when found positive was counted in one of four grades with one, two, three or four points respectively: one point indicating a few bacilli, four point a massive infection, and two and three points intermediate grades. The total of points at an examination is known as the "Bacteriological Index" or B.I., the maximum being 20 for the five smears."

Dharmendra adopts a similar method to that devised at Chingleput, but his method of estimating the number of bacilli is somewhat different, and he indicates the degree of positivity as slight, moderate, heavy and massive or in grades of $+\mathrm{I},+2,+3$, +4 , as under:-

"Slight " or $+(\mathrm{I}+)$

Bacilli not found in every field but only in an occasional field, and there are not more than two or three bacilli in a field perhaps with one or two small globi in 50 fields.

"Moderate" or $++(2+)$ Bacilli found in every field, but not more than about ten in each field with a few globi here and there.

"Heavy" or $+++(3+)$ Numerous bacilli and globi found in every field.

"Massive " or $++++(4+)$ Innumerable bacilli and large number of globi found in every field.

If a number of smears are examined and the degree of positivity varies, an average degree of positivity could be expressed in the form of a "bacteriological index" by adding the degrees of positivities of all the smears and dividing the total by the number of smears examined. For example, six smears taken from a case may give the following results:- 


$\begin{array}{rlllll}\text { Smear No. I. } & \text { Right ear } & \ldots & \ldots & 4+ \\ \text { Smear No. 2. } & \text { Left cheek } & \ldots & \ldots & 3+ \\ \text { Smear No. 3. } & \text { Chin } \ldots & \ldots & \ldots & 4+ \\ \text { Smear No. 4. } & \text { Right forearm } & \ldots & \ldots & 2+ \\ \text { Smear No. 5. } & \text { Left thigh } & \ldots & \ldots & 2+ \\ \text { Smear No. 6. } & \text { Nose } \ldots & \ldots & \ldots & 3+ \\ & \text { All six smears ... } & \text { I8 }\end{array}$

The index can be obtained by dividing 18 by 6 , i.e. the bacteriological index will be $\mathrm{r} 8 / 6=3 . "$

The chief objection to the index adopted for the Therapeutic Research Unit at Chingleput is that sixteen smears is too great a number to take from one individual, and time consuming and tedious. For ordinary purposes Dharmendra's method is one which can be recommended. Where detailed research in therapeutic remedies and careful assessment of results are necessary it seems logical that the greater the number of smears taken, and the higher the grading of the positivity of the slides, with the examination of at least Ioo fields, makes for more accurate appraisal of the results. Where a large number of patients are on therapeutic test the number of examinations is considerable, and therefore the routine smears have to be done by a technician. To be able to choose areas likely to be positive needs much experience and careful examination in a good light. Therefore our practice at Chingleput was to allow the technicians to smear all cases, and a careful check-up by the doctor in charge of research was undertaken every six months, when every patient was meticulously examined. By taking sixteen smears and grading the positivity of these from negative to six plus, we felt we reduced the margin of error to such an extent that our findings could be statistically analysed. It is hoped that in a future number of Leprasy Review an article will be published on " Principles of Clinical and Therapeutic Experiments in Leprosy, with particular reference to Sulphone Therapy." In this article will be included a statistical analysis of our findings, the statistical work having been done by a trained statistician.

This present article is written in order that workers may be aware of the different methods of assessing the bacteriological index, and to give them the opportunity to choose the method most suitable to their particular needs. The merits of these various methods cannot be assessed until statistical comparisons have been done. For work in therapeutic trials in leprosy, the greater the accuracy in estimating the progress towards a state of negativity the more sure 
will be the results, and thus one can guard against impressions and wishful thinking, all too common in leprosy, and which are liable to vitiate the final conclusions. 